\title{
Editorial
}

\section{La medición del mundo de los libros: escalas, proporciones, formatos y clasificaciones}

Un libro es un objeto. Como cualquier otro objeto, cuando se mira con cuidado se muestra como un complejo conjunto de elementos. Los libros son objetos industriales que deben ser ensamblados; son trabajos estéticos que deben ser diseñados; productos que tienen que ser vendidos; portadores de información que necesitan ser almacenados; bancos de conocimientos que podría ser distribuidos o censurados; repositorios de material con derechos de autor que requieren para ser protegidos; piezas de una biblioteca que se clasificó y catalogó; artículos en una estantería que debe encajar en su lugar. Para cumplir todas estas funciones los libros tienen que ser medidos, formateados, estandarizados y clasificados.

Los artículos de este número monográfico de Infodesign exploran el origen y el funcionamiento de las convenciones que utilizamos para medir y clasificar los libros. Los temas que se abordan van desde la medición de papel y la tipografía; episodios históricos sobre la disposición temprana de éstos en las bibliotecas de la América Española, hasta los actuales sistemas de clasificación empleados en los acervos y la copiosa cantidad de números impresos empleados para su identificación y control.

Los libros son sujetos para su medición y clasificación mediante dos procesos paralelos: la industrialización y la racionalización. Cuando Gutenberg "inventó" el tipo móvil no sólo abrió las puertas a la producción masiva de libros, sino también dio el disparo inicial a la industrialización. La industrialización —combinada con el comercio de larga distancia- requiere de un único conjunto de medidas para ser más eficaz. Los procesos industriales y la mecanización sustituyeron las formas tradicionales de producción de libros. Las técnicas de impresión modernas producen miles de libros idénticos, ajustados a las dimensiones que tienen que ser reguladas por mediciones precisas. Los libros - que se hicieron previamente de forma manual-comenzaron a producirse de forma masiva; y la estandarización de medidas comenzó a ser más ampliamente utilizada en el mundo del libro. Los nuevos métodos de producción conllevaron la necesidad de normalización; para hacerlos se requieren dos grupos de suministros básicos: el papel y los tipo para componer, de forma tal que se puedan adecuar a patrones y tamaños predefinidos, y acordes con la rápida evolución de la maquinaria de impresión moderna. Los artículos de Germán Fraustro 
Nadal y Oriol Moret Viñals muestran las intrincadas formas en que algunos de estos procesos de normalización se llevaron a cabo.

Por otro lado, el nuevo mundo de conocimiento que trajo aparejada la producción masiva de libros creó la demanda de métodos y sistemas para ordenar y clasificar esa enorme cantidad de información. A través de los siglos, se desarrollaron innumerables técnicas para organizar los libros en las bibliotecas y repositorios, en una búsqueda que finalmente reflejaba los proyectos para clasificar y organizar todo el conocimiento humano. Aparecieron muchos sistemas racionales de clasificación libro - por racional nos referimos a sistemas rigurosos, metódicos, coherentes y predecibles- con la esperanza de hacer que la información sea más fácil de almacenar, rastrear y recuperar. Los artículos de Manuel Suárez Rivera, Víctor Cid Carmona y Claudia Escobar Vallarta, y Héctor Vera muestran el funcionamiento de algunos de los sistemas, del pasado y el presente.

Los estudios reunidos en este número especial Infodesign apuntan a un tema específico del diseño y han sido elaborados desde diferentes disciplinas científicas y académicas, en la que el libro, en tanto artefacto cultural, y su medición se convierten en un área de interés y la reflexión central del diseño de información.

Esperamos que esta compilación sea de interés para los lectores y que los artículos reunidos nos permitan avanzar hacia nuevos terrenos para generar aportaciones críticas que vinculen el diseño de información y con los estudios del libro.

\section{Marina Garone Gravier y Héctor Vera}

Editores 